\title{
Rho-kinase regulates thrombin-stimulated interleukin-6 synthesis via p38 mitogen-activated protein kinase in osteoblasts
}

\author{
KENJI KATO ${ }^{1,2}$, TAKANOBU OTSUKA ${ }^{1}$, RIE MATSUSHIMA-NISHIWAKI ${ }^{2}$, \\ HIDEO NATSUME ${ }^{1,2}$, OSAMU KOZAWA ${ }^{2}$ and HARUHIKO TOKUDA ${ }^{2,3}$ \\ ${ }^{1}$ Department of Orthopedic Surgery, Nagoya City University Graduate School of Medical Sciences, Nagoya 467-8601; \\ ${ }^{2}$ Department of Pharmacology, Gifu University Graduate School of Medicine, Gifu 501-1194; ${ }^{3}$ Department \\ of Clinical Laboratory, National Center for Geriatrics and Gerontology, Obu 474-8511, Japan
}

Received April 14, 2011; Accepted May 20, 2011

DOI: $10.3892 /$ ijmm.2011.747

\begin{abstract}
We have previously reported that thrombin stimulates synthesis of interleukin-6 (IL-6), a potent bone resorptive agent, in osteoblast-like MC3T3-E1 cells. In the present study, we investigated the mechanism of thrombin in the thrombinstimulated IL-6 synthesis and the involvement of Rho-kinase in MC3T3-E1 cells. Thrombin time-dependently induced the phosphorylation of p44/p42 mitogen-activated protein (MAP) kinase, p38 MAP kinase, stress-activated protein kinase/c-Jun $\mathrm{N}$-terminal kinase (SAPK/JNK) and myosin phosphatase targeting subunit-1 (MYPT-1), a Rho-kinase substrate. While SP600125, an inhibitor of SAPK/JNK, failed to reduce IL-6 synthesis, PD98059, a specific inhibitor of MEK, and SB203580 and BIRB0796, potent inhibitors of 338 MAP kinase, suppressed the IL-6 synthesis induced by thrombin. Y27632, a specific Rho-kinase inhibitor, significantly reduced thrombin-stimulated IL-6 synthesis as well as the MYPT-1 phosphorylation. Fasudil, another inhibitor of Rho-kinase, suppressed thrombinstimulated IL-6 synthesis. Y27632 and fasudil failed to affect thrombin-induced phosphorylation of p44/p42 MAP kinase. Y27632 as well as fasudil attenuated thrombin-induced phosphorylation of p38 MAP kinase. These results strongly suggest that Rho-kinase regulates thrombin-stimulated IL-6 synthesis via p38 MAP kinase activation in osteoblasts.
\end{abstract}

\section{Introduction}

Interleukin-6 (IL-6) is a multifunctional and proinflammatory cytokine that has crucial effects on versatile functions such as promoting $\mathrm{B}$ cell differentiation, $\mathrm{T}$ cell activation and inducing acute phase proteins (1-3). The bone metabolism is regulated mainly by two functional cells, osteoblasts and osteoclasts,

Correspondence to: Dr Haruhiko Tokuda, Department of Clinical Laboratory, National Center for Geriatrics and Gerontology, Obu 474-8511, Japan

E-mail: tokuda@ncgg.go.jp

Key words: thrombin, Rho-kinase, mitogen-activated protein kinase, interleukin-6, osteoblast which are responsible for bone formation and bone resorption, respectively (4). In terms of bone metabolism, IL-6 has been shown to stimulate bone resorption and promote osteoclast formation $(2,3,5,6)$. It has been reported that potent bone resorptive agents, such as tumor necrosis factor- $\alpha$ and IL-1 stimulate IL- 6 synthesis in osteoblasts $(5,7,8)$. Currently, evidence is accumulating that IL-6 secreted from osteoblasts plays a pivotal role as a downstream effector of bone resorptive agents in bone metabolism.

It is well recognized that thrombin, a serine protease, plays a crucial role in blood coagulation cascade through its cleavage of fibrinogen to fibrin (9). Accumulating evidence suggests that thrombin has receptor-mediated effects on a variety of cells including osteoblasts via protease-activated receptors (PARs) (10). Furthermore, it has been shown that thrombin stimulates bone resorption (10). As for osteoblasts, thrombin reportedly stimulates their proliferation and IL-6 secretion, and suppresses alkaline phosphatase activity, a marker of osteoblast differentiation (10). We have previously shown that thrombin induces the activation of protein kinase $\mathrm{C}$ via the phosphatidylcholine-hydrolyzing phospholipase $\mathrm{D}$, but not of phosphoinositide-hydrolyzing phospholipase $\mathrm{C}$ in osteoblastlike MC3T3-E1 cells, and that its proliferative effect depends on phospholipase D activation (11). Regarding IL-6 synthesis in osteoblasts, we have reported that thrombin stimulates IL-6 synthesis via $\mathrm{Ca}^{2+}$ mobilization in osteoblast-like MC3T3-E1 cells (12). However, the exact mechanism behind the thrombinstimulated IL-6 synthesis in osteoblasts remains to be clarified.

Recent studies suggest that Rho and the downstream effector, Rho-associated kinase (Rho-kinase) play important roles in a variety of cellular functions such as cell motility and smooth muscle contraction (13-15). As for osteoblasts, it has been demonstrated that Rho-kinase and p38 mitogen-activated protein (MAP) kinase are involved in the endothelin-1-induced expression of prostaglandin endoperoxide $\mathrm{G} / \mathrm{H}$ synthase mRNA in osteoblasts (16). In addition, it has been shown that the Rho/Rho-kinase pathway stimulates osteoblast proliferation, whereas it inhibits osteoblast differentiation (17). We have previously reported that the basic fibroblast growth factor stimulates the activation of Rho-kinase in osteoblast-like MC3T3-E1 cells and that the kinase serves the role of a negative regulator in vascular endothelial growth factor 
release (18). However, the exact role of Rho-kinase in osteoblasts has not yet been fully elucidated.

In the present study, we investigated the exact mechanism behind thrombin-stimulated IL-6 synthesis in osteoblast-like MC3T3-E1 cells and the involvement of Rho-kinase in IL-6 synthesis. We here show that Rho-kinase positively regulates thrombin-stimulated IL-6 synthesis through p38 MAP kinase activation in these cells.

\section{Materials and methods}

Materials. Thrombin and mouse IL-6 enzyme-linked immunosorbent assay (ELISA) kits were purchased from R\&D Systems, Inc. (Minneapolis, MN). PD98059, SB203580 and SP600125 and Y27632 were obtained from Calbiochem-Novabiochem Co. (La Jolla, CA). Hydroxyfasudil (fasudil) was purchased from Sigma-Aldrich (St. Louis, MO). BIRB0796 was obtained from Dr Philip Cohen (University of Dundee, UK). Phosphospecific myosin phosphatase targeting subunit-1 (MYPT-1) antibodies were purchased from Millipore (Billerica, MA). The GAPDH antibodies were obtained from Santa Cruz Biotechnology, Inc. (Santa Cruz, CA). Phospho-specific p44/ p42 MAP kinase, p44/p42 MAP kinase, phospho-specific p38 MAP kinase, p38 MAP kinase, phospho-specific stressactivated protein kinase/c-Jun N-terminal kinase (SAPK/ $\mathrm{JNK}$ ) and SAPK/JNK antibodies were purchased from Cell Signaling Technology, Inc. (Beverly, MA). An ECL Western blotting detection system was purchased from GE Healthcare UK, Ltd. (Buckinghamshire, UK). Other materials and chemicals were obtained from commercial sources. Y27632, PD98059, SB203580, SP600125, BIRB0796 and Y27632 were dissolved in dimethyl sulfoxide. The maximum concentration of dimethyl sulfoxide was $0.1 \%$, which did not affect the assay for IL-6 or detection of protein level by a Western blot analysis.

Cell culture. Cloned osteoblast-like MC3T3-E1 cells derived from newborn mouse calvaria (19) were maintained as previously described (20). Briefly, the cells were cultured in $\alpha$-minimum essential medium ( $\alpha$-MEM) containing $10 \%$ fetal calf serum (FCS) at $37^{\circ} \mathrm{C}$ in a humidified atmosphere of $5 \% \mathrm{CO}_{2} / 95 \%$ air. The cells were seeded into $35-\mathrm{mm}\left(5 \times 10^{4}\right)$ or $90-\mathrm{mm}\left(2 \times 10^{5}\right)$ diameter dishes in $\alpha$-MEM containing $10 \%$ FCS. After 5 days, the medium was exchanged for $\alpha$-MEM containing $0.3 \%$ FCS. The cells were used for experiments after $48 \mathrm{~h}$.

IL-6 assay. The cultured cells were stimulated by $1 \mathrm{U} / \mathrm{ml}$ thrombin in $1 \mathrm{ml}$ of $\alpha$-MEM containing $0.3 \%$ FCS for the indicated periods. When indicated, the cells were pre-treated with various doses of Y27632, fasudil, PD98059, SB203580, BIRB0796 or SP600125 for 60 min. The conditioned medium was collected at the end of the incubation, and the IL- 6 concentration was measured by the IL-6 ELISA kit.

Western blot analysis. A Western blot analysis was performed as previously described (21). The cultured cells were stimulated by thrombin or vehicle in $\alpha$-MEM containing $0.3 \%$ FCS for the indicated periods. When indicated, the cells were pre-treated with various doses of Y27632 or fasudil for $60 \mathrm{~min}$. The cells were washed twice with phosphate-buffered saline and then lysed, homogenized and sonicated in a lysis buffer containing
$62.5 \mathrm{mM}$ Tris-HCl, $\mathrm{pH}$ 6.8; $3 \%$ sodium dodecyl sulfate (SDS), $50 \mathrm{mM}$ dithiothreitol and $10 \%$ glycerol. The cytosolic fraction was collected as a supernatant after centrifugation at $125,000 \mathrm{x} \mathrm{g}$ for $10 \mathrm{~min}$ at $4^{\circ} \mathrm{C}$. SDS-polyacrylamide gel electrophoresis (PAGE) was performed according to Laemmli (22) on $10 \%$ polyacrylamide gel. The protein $(20 \mu \mathrm{g})$ was fractionated and transferred onto an Immun-Blot PVDF Membrane (Bio-Rad, Hercules, CA). Membranes were blocked with 5\% fat-free dry milk in Tris-buffered saline-Tween (TBS-T; $20 \mathrm{mM}$ Tris- $\mathrm{HCl}$, $\mathrm{pH} 7.6,137 \mathrm{mM} \mathrm{NaCl}, 0.1 \%$ Tween-20) for $2 \mathrm{~h}$ before incubation with the primary antibodies. The rabbit polyclonal phosphospecific MYPT-1, MYPT-1, phospho-specific p44/p42 MAP kinase, p44/p42 MAP kinase, phospho-specific p38 MAP kinase, p38 MAP kinase, phospho-specific SAPK/JNK or SAPK/JNK antibodies were used as primary antibodies. Peroxidase-labeled antibodies raised in goat against rabbit IgG (KPL, Inc., Gaithersburg, MD) were used as secondary antibodies. The primary and secondary antibodies were diluted at 1:1000 with 5\% fat-free dry milk in TBS-T. Peroxidase activity on the membrane was visualized on X-ray film by means of the ECL Western blotting detection system.

Determination. The absorbance of the enzyme immunoassay samples was measured at $450 \mathrm{~nm}$ with the EL 340 Bio Kinetic Reader (BioTek Instruments, Inc., Winooski, VT).

Statistical analysis. The data were analyzed by ANOVA followed by the Bonferroni method for multiple comparisons between pairs, and a $\mathrm{P}<0.05$ was considered significant. All data are presented as the mean \pm SEM of triplicate independent determinations.

\section{Results}

Effects of thrombin on the phosphorylation of p44/p42 MAP kinase, p38 MAP kinase and SAPK/JNK in MC3T3-E1 cells. It is currently known that three MAP kinases, p44/p42 MAP kinase, p38 MAP kinase and SAPK/JNK are central elements used by mammalian cells to transduce the various messages of a variety of agonists (23). Therefore, we first examined the effect of thrombin on the activation of the p44/p42 MAP kinase, the p38 MAP kinase and of SAPK/JNK in the osteoblastlike MC3T3-E1 cells. Thrombin markedly induced the phosphorylation of p44/p42 MAP kinase, p38 MAP kinase and SAPK/JNK in a time-dependent manner (Fig. 1). The maximum effect of thrombin on the phosphorylation of p44/p42 MAP kinase reached its peak within 5 min after stimulation. On the other hand, the maximum effect of thrombin on the phosphorylation of p38 MAP kinase and SAPK/JNK were observed at 15 and 20 min after the stimulation, respectively (Fig. 1).

Effects of PD98059, SB203580, BIRB0796 or SP600125 on the thrombin-stimulated IL-6 synthesis in MC3T3-E1 cells. We have previously shown that thrombin stimulates IL-6 synthesis in osteoblast-like MC3T3-E1 cells (12). In order to investigate whether p44/p42 MAP kinase, p38 MAP kinase or SAPK/JNK are involved in thrombin-induced synthesis of IL-6 in MC3T3-E1 cells, we next examined the effect of PD98059, SB203580, BIRB0796 or SP600125 on the release of IL-6 induced by thrombin. PD98059, a MAP kinase extra- 
Table I. Effects of the inhibitors PD98059, SB203580, BIRB0796 or SP600125 on the thrombin-stimulated IL-6 synthesis in MC3T3-E1 cells.

\begin{tabular}{lcc}
\hline Inhibitors & Thrombin & IL-6 $(\mathrm{pg} / \mathrm{ml})$ \\
\hline 0 & - & $<7.8$ \\
0 & + & $160.0 \pm 20.4^{\mathrm{a}}$ \\
PD98059 $(30 \mu \mathrm{M})$ & - & $<7.8$ \\
PD98059 $(30 \mu \mathrm{M})$ & + & $36.4 \pm 2.1^{\mathrm{b}}$ \\
PD98059 $(50 \mu \mathrm{M})$ & - & $<7.8$ \\
PD98059 $(50 \mu \mathrm{M})$ & + & $34.0 \pm 2.1^{\mathrm{b}}$ \\
SB203580 $(10 \mu \mathrm{M})$ & - & $<7.8$ \\
SB203580 $(10 \mu \mathrm{M})$ & + & $26.3 \pm 1.8^{\mathrm{b}}$ \\
SB203580 $(30 \mu \mathrm{M})$ & - & $<7.8$ \\
SB203580 $(30 \mu \mathrm{M})$ & + & $23.1 \pm 2.3^{\mathrm{b}}$ \\
BIRB0796 $(0.3 \mu \mathrm{M})$ & - & $<7.8$ \\
BIRB0796 $(0.3 \mu \mathrm{M})$ & + & $75.2 \pm 18.0^{\mathrm{b}}$ \\
BIRB0796 $(1 \mu \mathrm{M})$ & - & $<7.8$ \\
BIRB0796 $(1 \mu \mathrm{M})$ & + & $49.7 \pm 8.7^{\mathrm{b}}$ \\
SP600125 $(10 \mu \mathrm{M})$ & - & $<7.8$ \\
SP600125 $(10 \mu \mathrm{M})$ & + & $161.1 \pm 15.9$ \\
\hline
\end{tabular}

The cultured cells were pretreated with various doses of PD98059, SB203580, BIRB0796 or SP600125 for $60 \mathrm{~min}$, and then stimulated with $1 \mathrm{U} / \mathrm{ml}$ thrombin or vehicle for $48 \mathrm{~h}$. Each value represents the mean \pm SEM of triplicate determinations. ${ }^{a} \mathrm{P}<0.05$, compared to the control; ${ }^{b} \mathrm{P}<0.05$, compared to the value of thrombin alone.

cellular signal-regulated protein kinase kinase inhibitor (24), significantly suppressed thrombin-stimulated IL-6 release (Table I). Thrombin-stimulated p44/p42 MAP kinase phosphorylation was inhibited by PD98059 (data not shown).

SB203580, an inhibitor of p38 MAP kinase (25), and BIRB0796, a more potent inhibitor of p38 MAP kinase than SB203580 (26), which attenuated the p38 MAP kinase phosphorylation by thrombin (data not shown), significantly reduced the IL-6 release by thrombin (Table I). On the contrary, SP600125, a specific inhibitor of SAPK/JNK (27), had little effect of IL-6 levels (Table I). We also found that SP600125 suppressed the thrombin-induced phosphorylation of SAPK/ JNK (data not shown).

Effects of thrombin on the phosphorylation of MYPT-1 in MC3T3-E1 cells. It is generally recognized that MYPT-1, which is a component of myosin phosphatase, is a well known substrate of Rho-kinase $(13,28)$. In order to investigate whether thrombin stimulates the activation of Rho-kinase in osteoblastlike MC3T3-E1 cells, we examined the effect of thrombin on the phosphorylation of MYPT-1. Thrombin remarkably induced the phosphorylation of MYPT-1 in a time-dependent manner (Fig. 2). The effect of thrombin on the phosphorylation of MYPT-1 reached its peak within $2 \mathrm{~min}$ and decreased thereafter (Fig. 2).

Y27632, a specific inhibitor of Rho-kinase (15), markedly attenuated thrombin-induced phosphorylation levels of

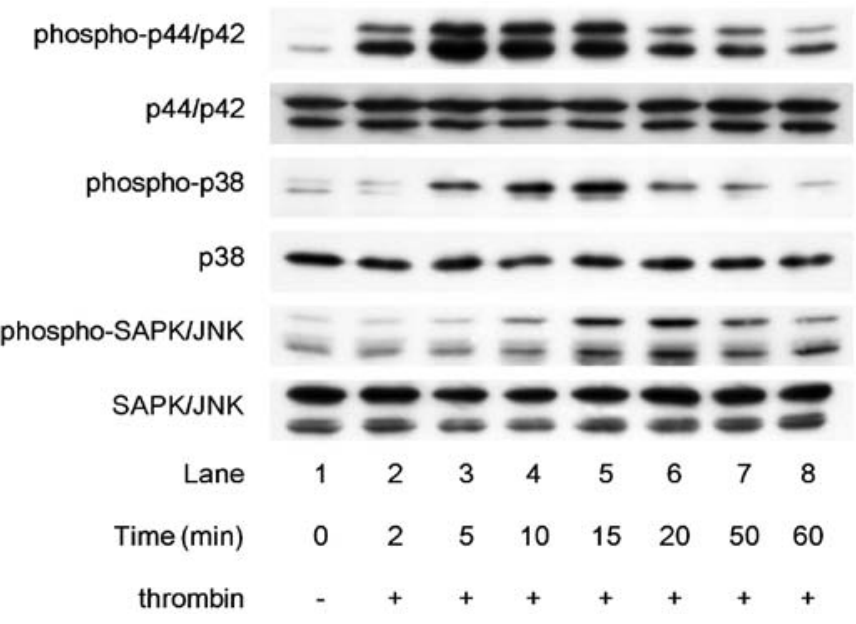

Figure 1. Effects of thrombin on the phosphorylation of p44/p42 MAP kinase, p38 MAP kinase and SAPK/JNK in MC3T3-E1 cells. The cultured cells were stimulated with $1 \mathrm{U} / \mathrm{ml}$ thrombin for the indicated periods. The cell extracts were subjected to SDS-PAGE with subsequent Western blot analysis with antibodies against phospho-specific p44/p42 MAP kinase, p44/p42 MAP kinase, phospho-specific p38 MAP kinase, p38 MAP kinase, phosphospecific SAPK/JNK or SAPK/JNK.

phospho-MYPT-1

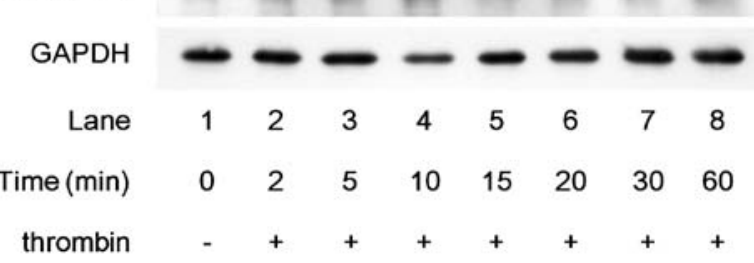

Figure 2. Effect of thrombin on the phosphorylation of MYPT-1 in MC3T3-E1 cells. The cultured cells were stimulated with $1 \mathrm{U} / \mathrm{ml}$ thrombin for the indicated periods. The cell extracts were subjected to SDS-PAGE with subsequent Western blot analysis with antibodies against phospho-specific MYPT-1 or GAPDH.

MYPT-1 (Fig. 3). In addition, we found that fasudil, another inhibitor of Rho-kinase (15), reduced thrombin-induced levels of MYPT-1 phosphorylation (data not shown).

Effects of Y27632 or fasudil on thrombin-stimulated IL-6 synthesis in MC3T3-E1 cells. In order to investigate whether Rho-kinase is involved in thrombin-induced synthesis of IL-6 in osteoblast-like MC3T3-E1 cells, we next examined the effect of Y27632 on the thrombin-induced release of IL-6. Y27632, which alone had little effect on the IL-6 levels, significantly suppressed the release of IL-6 induced by thrombin (Fig. 4). Y27632 $(20 \mu \mathrm{M})$ inhibited the thrombin-effect by $\sim 80 \%$.

Fasudil as well as Y27632, which by itself did not affect IL-6 levels, reduced the thrombin-stimulated IL-6 release in MC3T3-E1 cells (Fig. 5). Fasudil (10 $\mu \mathrm{M})$ inhibited the thrombin-effect by $\sim 80 \%$.

Effects of Y27632 or fasudil on thrombin-induced phosphorylation of $p 44 / p 42$ MAP kinase in MC3T3-E1 cells. In order to clarify whether the Rho-kinase-effect on the thrombinstimulated IL-6 synthesis is dependent upon the activation of 


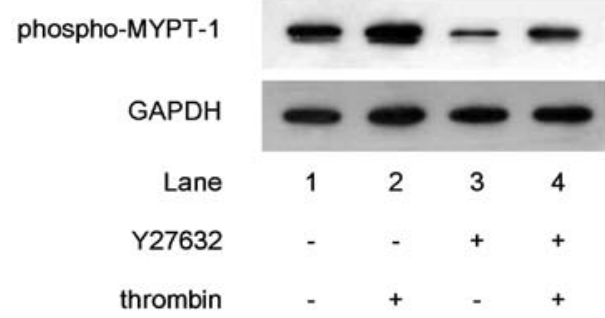

Figure 3. Effect of Y27632 on the thrombin-induced phosphorylation of MYPT-1 in MC3T3-E1 cells. The cultured cells were pretreated with $10 \mu \mathrm{M}$ Y27632 or vehicle for $60 \mathrm{~min}$, and then stimulated with $1 \mathrm{U} / \mathrm{ml}$ thrombin or vehicle for $2 \mathrm{~min}$. The extracts of cells were subjected to SDS-PAGE with subsequent Western blot analysis with antibodies against phospho-specific MYPT-1 or GAPDH.

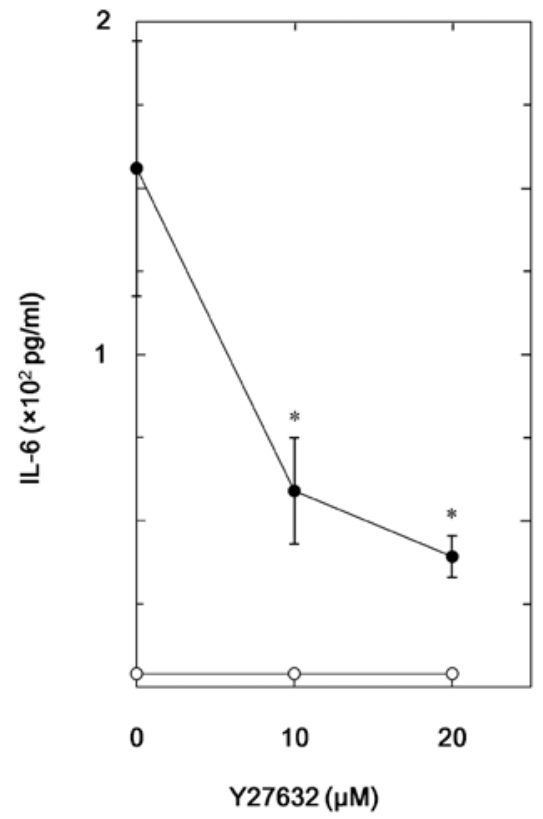

Figure 4. Effect of Y27632 on the thrombin-induced IL-6 synthesis in MC3T3-E1 cells. The cultured cells were pretreated with various doses of Y27632 for $60 \mathrm{~min}$, and then stimulated with $1 \mathrm{U} / \mathrm{ml}$ thrombin or vehicle for $48 \mathrm{~h}$. Each value represents the mean \pm SEM of triplicate independent determinations. " $\mathrm{P}<0.05$, compared to the value of thrombin alone.

p44/p42 MAP kinase in MC3T3-E1 cells, we next examined the effect of Y27632 on the phosphorylation of p44/p42 MAP kinase by thrombin. However, Y27632 at 1-10 $\mu \mathrm{M}$, failed to affect the thrombin-induced phosphorylation of p44/p42 MAP kinase (Fig. 6A). Additionally, fasudil had little effect on the phosphorylation levels of p44/p42 MAP kinase (Fig. 6B).

Effects of Y27632 or fasudil on thrombin-induced phosphorylation of p38 MAP kinase in MC3T3-El cells. In addition, we examined the effect of Y27632 on the thrombin-induced phosphorylation of p38 MAP kinase in MC3T3-E1 cells. Y27632, between 1 and $10 \mu \mathrm{M}$, markedly suppressed the phosphorylation of p38 MAP kinase induced by thrombin (Fig. 7A). Fasudil as well as Y27632 attenuated the increase in the levels of phosphorylated-p38 MAP kinase induced by thrombin (Fig. 7B).

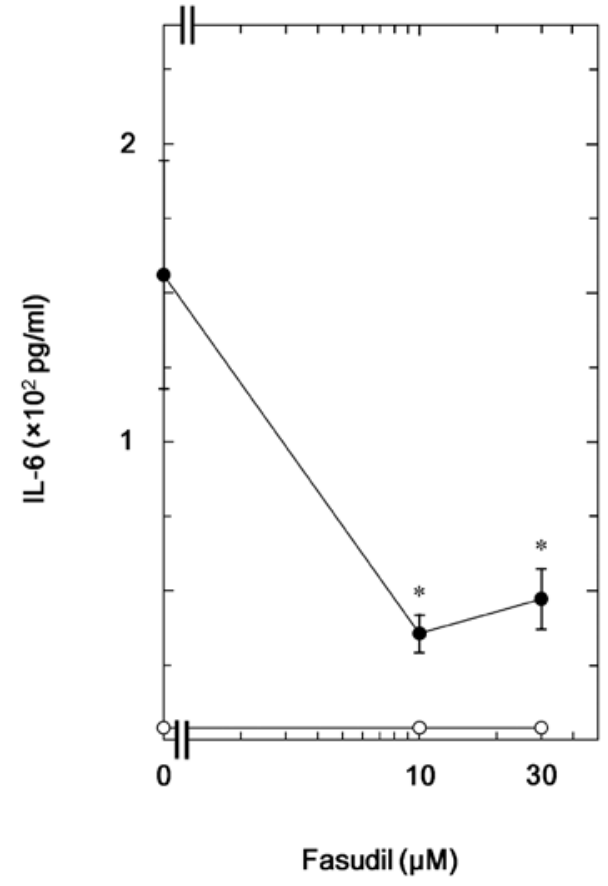

Figure 5. Effect of fasudil on the thrombin-induced IL-6 synthesis in MC3T3-E1 cells. The cultured cells were pretreated with various doses of fasudil for $60 \mathrm{~min}$, and then stimulated with $1 \mathrm{U} / \mathrm{ml}$ thrombin or vehicle for $48 \mathrm{~h}$. Each value represents the mean \pm SEM of triplicate independent determinations. ${ }^{*} \mathrm{P}<0.05$, compared to the value of thrombin alone.

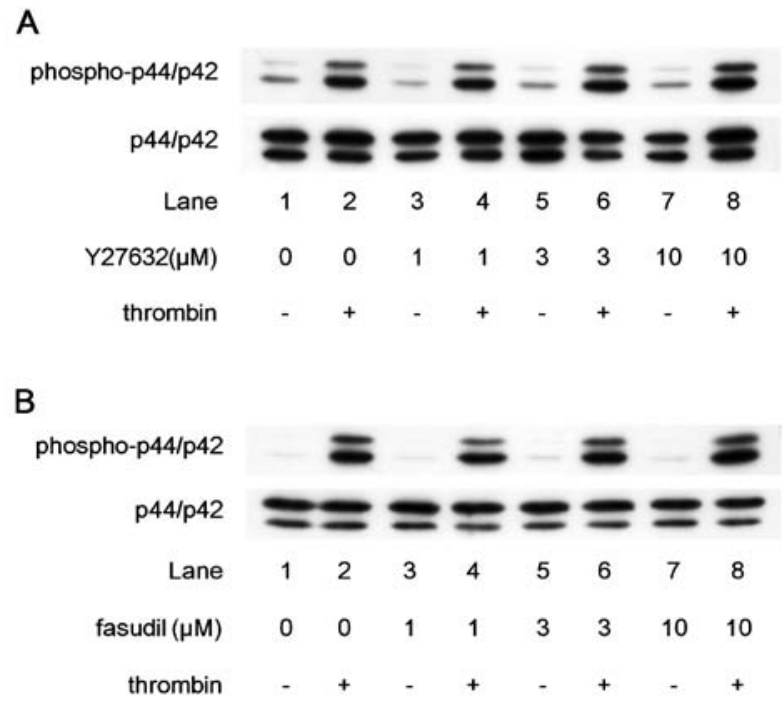

Figure 6. Effects of Y27632 or fasudil on the thrombin-induced phosphorylation of p44/p42 MAP kinase in MC3T3-E1 cells. The cultured cells were pretreated with various doses of Y27632 (A) or fasudil (B) for $60 \mathrm{~min}$, and then stimulated with $1 \mathrm{U} / \mathrm{ml}$ thrombin or vehicle for $5 \mathrm{~min}$. The cell extracts were subjected to SDS-PAGE with subsequent Western blot analysis with antibodies against phospho-specific p44/p42 MAP kinase or p44/p42 MAP kinase.

\section{Discussion}

In the present study, we demonstrated that the phosphorylation of p44/p42 MAP kinase, p38 MAP kinase and SAPK/JNK, major MAP kinases were remarkably induced by thrombin in osteoblast-like MC3T3-E1 cells. The MAP kinase superfamily 
A

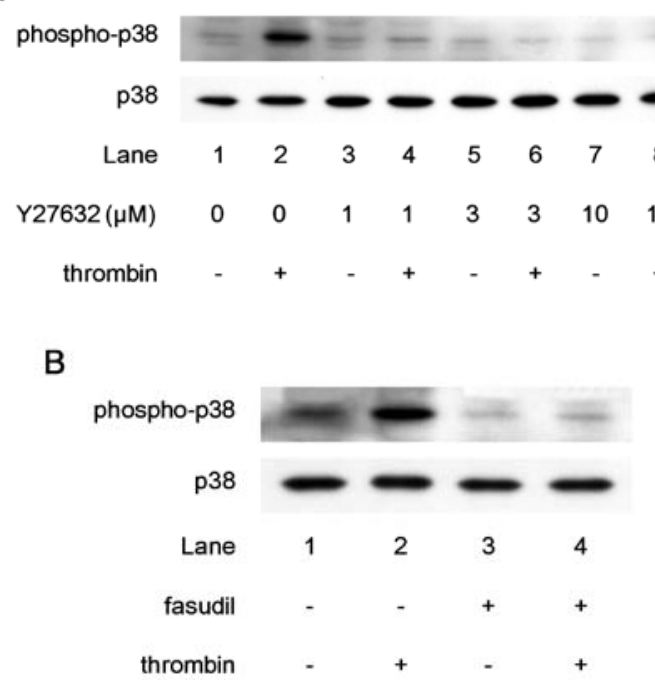

Figure 7. Effects of Y27632 or fasudil on the thrombin-induced phosphorylation of $\mathrm{p} 38$ MAP kinase in MC3T3-E1 cells. The cultured cells were pretreated with various doses of Y27632 (A) or fasudil (B) for $60 \mathrm{~min}$, and then stimulated with $1 \mathrm{U} / \mathrm{ml}$ thrombin or vehicle for $15 \mathrm{~min}$. The cell extracts were subjected to SDS-PAGE with subsequent Western blot analysis with antibodies against phospho-specific p38 MAP kinase or p38 MAP kinase.

plays crucial roles in a variety of cell functions. It is well known that MAP kinases are activated with the dual phosphorylation of threonine and tyrosine residues by a specific MAP kinase (23). Thus, it is probable that thrombin stimulates the activation of three MAP kinases in osteoblast-like MC3T3-E1 cells. We investigated the involvement of the MAP kinases in the IL-6 synthesis. Thrombin-stimulated IL-6 release was suppressed by PD98059, a specific inhibitor of MEK (24), or SB203580 or BIRB0796, specific inhibitors of p38 MAP kinase $(25,26)$, while SP600125, a specific inhibitor of SAPK/ JNK (27), failed to affect the IL-6 release. Therefore, our results suggest that thrombin stimulates IL-6 synthesis via p44/p42 MAP kinase and p38 MAP kinase in osteoblasts.

In addition, we showed that thrombin time-dependently induced the phosphorylation of MYPT-1 in osteoblast-like MC3T3-E1 cells. It is generally recognized that MYPT, a myosin-binding subunit of myosin phosphatase, regulates the interaction of actin and myosin, is a downstream target of Rho-kinase $(13,28)$. Additionally, we next found that Y27632 and fasudil, inhibitors of Rho-kinase (15), truly attenuated thrombin-induced phosphorylation levels of MYPT-1. Taking our results into account, it is most likely that thrombin induces the activation of Rho-kinase in osteoblast-like MC3T3-E1 cells.

We next investigated the involvement of Rho-kinase in the thrombin-stimulated IL-6 synthesis in osteoblast-like MC3T3-E1 cells. The thrombin-stimulated release of IL-6 was significantly suppressed by Y27632 (15). This finding suggests that the thrombin-activated Rho-kinase is implicated in the IL-6 synthesis in MC3T3-E1 cells. In addition, we showed that fasudil (15) as well as Y27632 reduced the IL-6 levels stimulated by thrombin. Therefore, our results indicate, that it is most likely that thrombin activates Rho-kinase, which acts as a positive regulator in the IL-6 synthesis in osteoblast-like MC3T3-E1 cells.

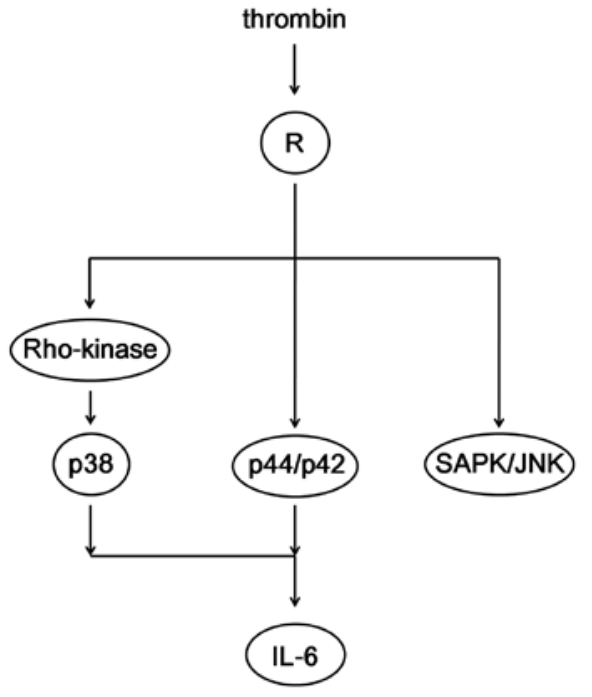

Figure 8 . The diagram of the regulatory mechanism of thrombin-stimulated IL-6 synthesis in osteoblasts.

We further investigated the relationship between Rho-kinase and the MAP kinase signaling, p44/p42 MAP kinase or $\mathrm{p} 38$ MAP kinase in the thrombin-stimulated IL-6 synthesis in osteoblast-like MC3T3-E1 cells. Y27632 or fasudil failed to affect thrombin-induced phosphorylation levels of p44/p42 MAP kinase. Therefore, it seems unlikely that Rho-kinase regulates the thrombin-stimulated IL-6 synthesis through the modulation of p44/p42 MAP kinase in these cells. On the contrary, thrombin-induced p38 MAP kinase phosphorylation was markedly suppressed by Y27632 or fasudil. Based on our results, it is most likely that Rho-kinase regulates thrombinstimulated IL-6 synthesis via p38 MAP kinase but not p44/ p42 MAP kinase in osteoblast-like MC3T3-E1 cells. In the present study, we showed that the maximum effect of thrombin on the phosphorylation of MYPT-1 was observed within 2 min after the stimulation. On the other hand, the phosphorylation of p38 MAP kinase reached the peak at 15 min after the stimulation of thrombin. The time course of thrombininduced phosphorylation of MYPT-1 seems to be faster than that of p38 MAP kinase. Thus, it seems reasonable that the thrombin-induced activation of p38 MAP kinase occurs after the Rho-kinase activation. Overall, our results suggest that Rho-kinase functions upstream from p38 MAP kinase and regulates the thrombin-stimulated IL-6 synthesis in osteoblastlike MC3T3-E1 cells. The speculated diagram of the regulatory mechanism of the thrombin-stimulated IL- 6 synthesis in osteoblasts is shown in Fig. 8.

Accumulating evidence indicates that Rho-kinase plays a pivotal role in not only vascular smooth muscle contraction but also in a variety of cellular functions (13-15). Regarding the osteoblasts, it has been shown that the activated Rho-kinase acts as a suppressive regulator in the differentiation of osteoblasts, while it directs them toward proliferation (17). Our present results suggest that Rho-kinase in osteoblasts functions as a positive regulator in thrombin-stimulated IL-6 synthesis. It is well known that IL-6 produced by osteoblasts is a potent bone resorptive agent and induces osteoclast formation $(3,5)$. On the other hand, it is recognized that thrombin, an inducer 
of IL-6, acts as a bone resorptive agent in bone metabolism (10). Therefore, our present findings lead us to speculate that thrombin-activated Rho-kinase in osteoblasts functions as a positive regulator of bone resorption via the fine-tuning of the local cytokine network, such as synthesis of IL-6. The Rho-kinase signaling pathway in osteoblasts might be a new candidate as a molecular therapeutic target of fracture healing and bone metabolic disease, such as osteoporosis. The exact role of Rho-kinase in bone metabolism has not yet been precisely clarified. Further investigations are necessary to elucidate the detailed roles of Rho-kinase in bone metabolism.

In conclusion, our results strongly suggest that thrombin stimulates the activation of p38 MAP kinase via Rho-kinase and regulates IL- 6 synthesis through the activation of p38 kinase in osteoblasts.

\section{Acknowledgements}

We are very grateful to Yoko Kawamura for her skillful technical assistance. This investigation was supported in part by a Grant-in-Aid for Scientific Research (16590873 and 16591482) for the Ministry of Education, Science, Sports and Culture of Japan, The Foundation for Growth Science and The Research Funding for Longevity Sciences (21A-4 and 22A-22) from the National Center for Geriatrics and Gerontology (NCGG), Japan.

\section{References}

1. Akira S, Taga $\mathrm{T}$ and Kishimoto T: Interleukin-6 in biology and medicine. Adv Immunol 54: 1-78, 1993.

2. Heymann D and Rousselle AV: gp130 cytokine family and bone cells. Cytokine 12: 1455-1468, 2000.

3. Kwan Tat S, Padrines M, Theoleyre S, Heymann D and Fortun Y: IL-6, RANKL, TNF-alpha/IL-1: interrelations in bone resorption pathophysiology. Cytokine Growth Factor Rev 15: 49-60, 2004.

4. Nijweide PJ, Burger EH and Feyen JHM: Cells of bone: proliferation, differentiation, and hormonal regulation. Physiol Rev 86 855-886, 1986.

5. Ishimi Y, Miyaura C, Jin CH, Akatsu T, Abe F, Nakamura Y, Yamaguchi Y, Yoshiki S, Matsuda T, Hirano T, Kishimoto T and Suda T: IL-6 is produced by osteoblasts and induces bone resorption. J Immunol 145: 3297-3303, 1990.

6. Roodman GD: Interleukin-6: an osteotropic factor? J Bone Miner Res 7: 475-478, 1992.

7. Littlewood AJ, Russil J, Harvey GR, Hughes DE, Russel RG and Gowen M: The modulation of the expression of IL- 6 and its receptor in human osteoblasts in vitro. Endocrinology 129: 1513-1520, 1991.

8. Helle M, Brakenhoff JP, De Groot ER and Aarden LA: Interleukin 6 is involved in interleukin 1-induced activities. Eur J Immunol 18: 957-959, 1998.

9. Lane DA, Philippou H and Huntington JA: Directing thrombin. Blood 106: 2605-2612, 2005.

10. Mackie EJ, Loh LH, Sivagurunathan LS, Uaesoontrachoon K, Yoo HJ, Wong D, Georgy SR and Pagel CN: Protease-activated receptors in the musculoskeletal system. Int J Biochem Cell Biol 40: 1169-1184, 2008.
11. Suzuki A, Kozawa O, Shinoda J, Watanabe Y, Saito H and Oiso Y: Thrombin induces proliferation of osteoblast-like cells through phosphatidylcholine hydrolysis. J Cell Physiol 168: 209-216, 1996.

12. Kozawa O, Tokuda H, Kaida T, Matsuno H and Uematsu T: Thrombin regulates interleukin-6 synthesis through phosphatidylcholine hydrolysis by phospholipase D in osteoblasts. Arch Biochem Biophys 345: 10-15, 1997.

13. Fukata Y, Amano M and Kaibuchi K: Rho-Rho-kinase pathway in smooth muscle contraction and cytoskeletal reorganization of non-muscle cells. Trends Pharmacol Sci 22: 32-39, 2001.

14. Riento K and Ridley AJ: Rocks: multifunctional kinases in cell behaviour. Nat Rev Mol Cell Biol 4: 446-456, 2003.

15. Shimokawa $H$ and Rashid M: Development of Rho-kinase inhibitors for cardiovascular medicine. Trends Pharmacol Sci 28: 296-302, 2007.

16. Windischhofer W, Zach D, Fauler G, Raspotnig G, Kofeler H and Leis HJ: Involvement of Rho and p38 MAPK in endothelin1-induced expression of PGHS-2 mRNA in osteoblast-like cells. J Bone Miner Res 17: 1774-1784, 2002.

17. Harmey D, Stenbeck G, Nobes CD, Lax AJ and Grigoriadis AE: Regulation of osteoblast differentiation by Pasteurella multocida toxin (PMT): a role for Rho GTPase in bone formation. J Bone Miner Res 19: 661-670, 2004

18. Natsume H, Tokuda H, Adachi S, Takai S, Matsushima-Nishiwaki R, Kato K, Minamitani C,Niida S, Mizutani J, Kozawa O and Otsuka T: Rho-kinase limits FGF-2-stimulated VEGF release in osteoblasts. Bone 46: 1068-1074, 2010.

19. Sudo H, Kodama H, Amagai Y, Yamamoto S and Kasai S: In vitrodifferentiation and calcification in a new clonalosteogenic cell line derived from newborn mouse calvaria. J Cell Biol 96: 191-198, 1983.

20. Kozawa O, Tokuda H, Miwa M, Kotoyori J and Oiso Y: Cross-talk regulation between cyclic AMP production and phosphoinositide hydrolysis induced by prostaglandin E2 in osteoblast-like cells. Exp Cell Res 198: 130-134, 1992.

21. Kato K, Ito H, Hasegawa K, Inaguma Y, Kozawa O and Asano T: Modulation of the stress-induced synthesis of hsp27 and $\alpha \mathrm{B}$-crystallin by cyclic AMP in C6 rat glioma cells. J Neurochem 66: 946-950, 1996.

22. Laemmli UK: Cleavage of structural proteins during the assembly of the head of bacteriophage T4. Nature 227: 680-685, 1970.

23. Widmann C, Gibson S, Jarpe MB and Johnson GL: Mitogenactivated protein kinase: conservation of a three-kinase module from yeast to human. Physiol Rev 79: 143-180, 1999.

24. Alessi DR: PD098059 is a specific inhibitor of the activation of mitogen-activated protein kinase in vitro and in vivo. J Biol Chem 270: 27489-27494, 1995.

25. Cuenda A, Rouse J, Doza YN, Meier R, Cohen P, Gallagher TF, Young PR and Lee JC: SB203580 is a specific inhibitor of a MAP kinase homologue which is stimulated by cellular stresses and interleukin-1. FEBS Lett 364: 229-233, 1995.

26. Bain J, Plater L, Matt E, Shpiro N, Hastie J, McLauchlan H, Klevernic I, Arthur S, Alessi D and Cohen P: The selectivity of protein kinase inhibitors; a further update. Biochem J 408: 297-315, 2007.

27. Bennett BL, Sasaki DT, Murray BW, O'Leary EC, Sakata ST, $\mathrm{Xu}$ W, Leisten JC, Motiwala A, Pierce S, Satoh Y, Bhagwat SS, Manning AM and Anderson DW: SP600125, an anthrapyrazolone inhibitor of Jun N-terminal Kinase. Proc Natl Acad Sci USA 98: 13681-13686, 2001.

28. Ito M, Nakano T, Erdodi F and Hartshorne DJ: Myosin phosphatase: structure, regulation and function. Mol Cell Biochem 259: 197-209, 2004. 